\title{
Core Design of Breed \& Burn Molten Salt Fast Reactor
}

\author{
Eduardo Cuoc ${ }^{* 1}$, Eugene Shwageraus², Alisha Kasam³, Ian $\operatorname{Scott}^{4}$ \\ ${ }^{12}$ Department of Engineering, University of Cambridge \\ Trumpington Street, Cambridge, CB2 1PZ, United Kingdom
}

${ }^{4}$ Moltex Energy Ltd.

13 The Courtyard, Timothy's Bridge Road, Stratford-upon-Avon, CV37 9NP, United Kingdom

ec600@cam.ac.uk, es607@cam.ac.uk, aak52@cam.ac.uk and ianscott@moltexenergy.com

\begin{abstract}
Previous designs of once-through solid-fuelled breed-and-burn (B\&B) reactor and the conventional molten salt reactor (MSR) concepts suffer from material limitation of neutron irradiation damage and chemical corrosion. A novel breed-and-burn molten salt reactor (BBMSR) concept uses separate molten salt fuel and coolant in a linear assembly core configuration. Similar to Moltex Energy Stable Salt Reactor (SSR) design, the configuration with fuel salt contained in fuel tubes and coolant salt in pool type reactor vessel has been previously studied. The study confirmed that breed-and-burn operation is feasible in principle, however with a low neutronic margin. The objective of this paper was to seek improvements of the neutronic margin with a metallic natural uranium blanket design. A parametric study was performed for the natural uranium blanket design. BBMSR neutronic performance simulation was modelled using Serpent, a Monte Carlo reactor physics code, with a single 3D hexagonal channel containing a single fuel tube in an infinite lattice with reflective radial and vacuum axial boundary conditions. The addition of a metallic natural uranium blanket inside the fuel tube, which increases the natural uranium metal to fuel salt ratio $(\Upsilon)$ of the BBMSR, was shown to significantly increase the neutronic performance of the BBMSR.
\end{abstract}

\section{INTRODUCTION}

The current Light Water Reactor (LWR) with a once-through and partially closed fuel cycle have the disadvantage of low fuel utilization. Fast breeder reactor (FBR) offers higher fuel utilization but requires fuel reprocessing, increasing the risk of nuclear proliferation. The once-through solid-fuelled breed-andburn (B\&B) fast reactor demands no fuel enrichment nor reprocessing, however, the high level of burn up required for breed-and-burn operation exceeds the current established material fluence limitation [1]. The conventional pumped fuel molten salt reactor (MSR) potentially offers passively safe and efficient nuclear energy with high fuel utilization and low proliferation risk. However, complex corrosion behaviour, delayed neutron precursor drift, and tritium production in lithium-based salts remain major challenges of MSR [2]. The stable salt reactor (SSR) by Moltex Energy LLP is a molten salt fast reactor designed as a waste burner to operate with separate molten fuel and coolant salt in a linear assembly core configuration [3]. The fuel tubes are similar to the fuel pins used in a traditional LWR linear assembly, however, a larger diameter is possible due to improved heat transfer by natural circulation of the fuel salt. Each fuel assembly contains

\footnotetext{
*Author's alternative email address: ec600@alumni.cam.ac.uk
} 
bundles of fuel tubes where the fuel salt is contained, and the coolant salt is in a pool-type reactor vessel (Fig. 1). This configuration avoids the complex engineering and corrosion issue of pumping actinidebearing molten salt fuel. The breed-and-burn molten salt reactor (BBMSR) design is based on a modified SSR design by using natural uranium fuel salt to achieve breed-and-burn operation [4]. The BBMSR must breed enough fissile plutonium to achieve self-sustaining breed-and-burn operation over the fuel residence time. To maximize plutonium breeding, a hard neutron spectrum was achieved by using $100 \%$ enriched ${ }^{37} \mathrm{Cl}$ chloride fuel and coolant salts, as ${ }^{37} \mathrm{Cl}$ has a lower neutron capture cross-section comparing to ${ }^{35} \mathrm{Cl}$, and lower scattering cross-section and slowing down decrement than fluoride salt [4]. For breed-and-burn operation to be possible, the BBMSR must be a net neutron producer at the discharge burnup. The BBMSR feasibility study confirms that breed-and-burn operation is possible in principle, however with a low margin [4]. The aim of this work is to increase the neutron excess margin of the BBMSR using metallic natural uranium as a breeding blanket inside the fuel tube design. The results of the neutron excess analysis and parametric studies of the BBMSR fuel tube and blanket design are presented in this paper.

\section{BBMSR PARAMETERS AND SPECIFICATIONS}

This paper is based on the BBMSR design described in ref. [4] using $100 \% \mathrm{UCl}_{3}$ as the molten fuel salt with natural uranium $\left(0.7 \%{ }^{235} \mathrm{U}\right)$ and fuel power density of $250 \mathrm{~W} / \mathrm{cm}^{3}$. The fuel salt is composed of ${ }^{235} \mathrm{U}$, ${ }^{238} \mathrm{U}$ and ${ }^{37} \mathrm{Cl}$ with atomic density (atom/barn $\mathrm{cm}$ ) of 5.03E-05, 7.14E-03 and $2.16 \mathrm{E}-02$ respectively. The coolant salt is a ternary eutectic chloride salt mixture of $\mathrm{MgCl}_{2}, \mathrm{NaCl}$, and $\mathrm{KCl}$ (50-30-20mol\%) composed of ${ }^{24} \mathrm{Mg},{ }^{23} \mathrm{Na},{ }^{39} \mathrm{~K}$ and ${ }^{37} \mathrm{Cl}$ with the respective atomic density (atom/barn $\mathrm{cm}$ ) of $5.91 \mathrm{E}-03,3.55 \mathrm{E}-03$, $2.36 \mathrm{E}-03$ and $1.77 \mathrm{E}-02$. The fuel tube has an inner radius of $2.45 \mathrm{~cm}$ and cladding thickness $0.05 \mathrm{~cm}$ using natural molybdenum (Mo) with atomic density (atom/barn $\mathrm{cm}$ ) of 6.52E-02. The hexagonal pin pitch is $5.02 \mathrm{~cm}$. Fig. 2 gives an example of a single hexagonal channel of the BBMSR.

\section{BBMSR SERPENT MODEL}

The Serpent Monte Carlo reactor physics code was used for the BBMSR simulation with nuclear data library ENDF/B-VII.0 [5]. The BBMSR was modelled using a single 3D hexagonal pin cell in an infinite lattice (Fig. 3), with vacuum axial boundaries to simulate neutron leakage. Fig. 4 shows the axial crosssectional view of the BBMSR, where the fuel salt is shown in green, upper coolant salt in orange, cladding in purple and void in black. Only the top half of the core was modelled with a reflective boundary at the plane of symmetry. The fuel, coolant, and cladding were modelled at 1200, 900, and $900 \mathrm{~K}$, respectively.

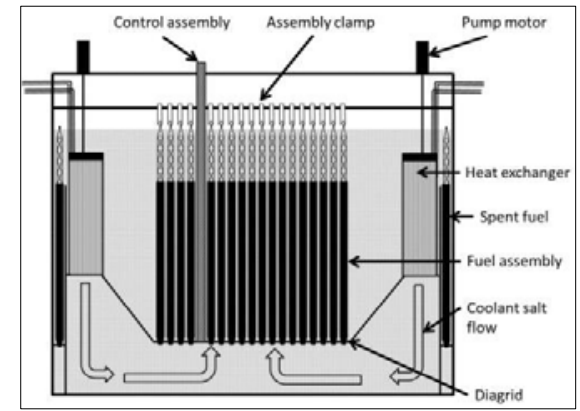

Figure 1. Side view of Moltex SSR reactor [3].

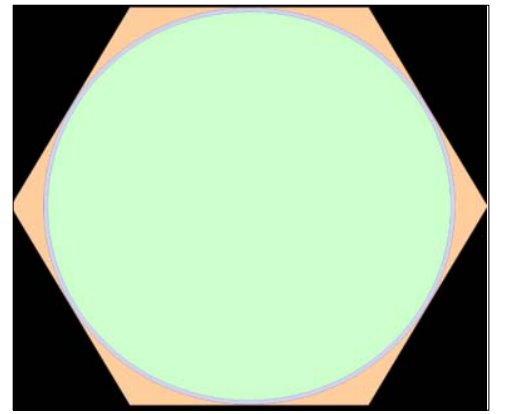

Figure 2. Single hexagonal channel.

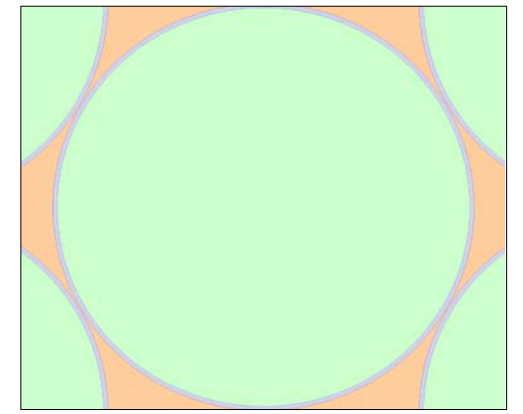

Figure 3. Infinite $x-y$ lattice.

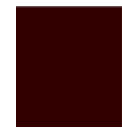


Figure 4. Axial cross-sectional illustration of a BBMSR fuel tube (top half sectional view).

\subsection{Breeding blanket design}

Metallic natural uranium breeding blankets were added to the fuel tube design to improve the neutronic performance of the BBMSR. The blanket was modelled at a temperature of $900 \mathrm{~K}$ and composed of ${ }^{234} \mathrm{U}$, ${ }^{235} \mathrm{U}$ and ${ }^{238} \mathrm{U}$ with atomic density (atom/barn $\mathrm{cm}$ ) of 2.65E-06, 3.53E-04 and 4.80E-02 respectively. The conventional axial breeding blanket design was first considered which consists of an upper and lower natural uranium blanket. Similar to the axial blankets of a fast breeder reactor, the blankets are located at the top and bottom of the fuel tube (shown in blue in Fig. 5 to 6). Serpent modelling showed that this option was unfeasible as the blanket becomes the predominant location of power generation over the lifetime of the burnup fuel cycle. The low surface-to-volume ratio of the blanket will result in insufficient cooling and lead to the melting of the blanket. A concentric natural uranium tubular breeding blanket (U-Tube) design, fixed inside the fuel tube (Fig. 7 to 9), was considered instead.

Figure 5. Axial breeding blanket of the BBMSR.

Figure 7. BBMSR with U-Tube blanket (8 regions).

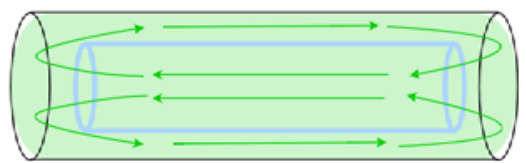

Figure 8. Natural circulation of fuel salt with $\mathrm{U}$ Tube fixed inside a (vertical) fuel tube.

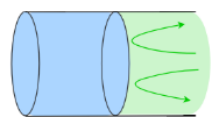

Figure 6. Axial blanket.

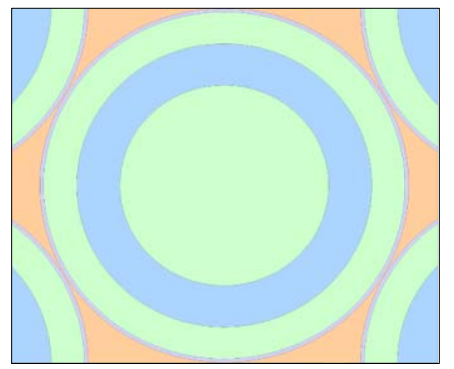

Figure 9. Top view U-Tube BBMSR lattice.

\section{PLUTONIUM DIFFUSION AND BOUNDING CASES}

Analysis was performed to estimate the neutronic effect of fissile plutonium bred in the blankets diffusing into the fuel salt. Previous study of self-diffusion of gamma phase uranium suggested a self-diffusion constant of around $10^{-8} \mathrm{~cm}^{2}$ with the diffusion of ${ }^{235} \mathrm{U}$ into ${ }^{238} \mathrm{U}$ at a rate of $1 \mathrm{~mm}$ per hour [7]. The selfdiffusion of plutonium in gamma uranium is speculated to be even higher, and the Gibbs free energy of the chemical reaction suggests that $\mathrm{PuCl}_{3}$ production is strongly favoured at all temperatures [8]. However, further research is required as there is currently a lack of literature on this topic. The motivations for the UTube blanket geometry are listed as follows; 1) To reduce the diffusion distance required for plutonium atoms bred inside the blanket to reach the surface of the blanket. 2) To promote breeding ratio and improve axial power distribution with a blanket extending almost the length of the fuel tube. 3) To improve cooling of the blanket by increasing its surface-to-volume ratio. 4) To stabilise the natural circulation of the fuel salt inside the fuel tube, where salt flows upward within the inner channel and downward along the outside of the U-Tube blanket due to the temperature distribution and volumetric expansion in the fuel salt (Fig. 8) [6]. To capture the spatial effects of breed-and-burn operation of the fuel salt and blanket region, the Serpent model of the top half of the fuel and U-Tube was axially sub-divided into 8 different burnable regions (see Fig. 7). For the purpose of this study, two bounding cases for plutonium diffusion to the surface of the blanket and into the $\mathrm{UCl}_{3}$ fuel salt were assumed: 1) Maximum plutonium diffusion - All plutonium atoms bred inside the blanket will exchange instantaneously with $\mathrm{UCl}_{3}$ into the fuel salt to form $\mathrm{PuCl}_{3}$ at every 
burnup time step (upper bounding case). 2) Zero plutonium diffusion - No exchange of plutonium from the blanket into the fuel salt (lower bounding case). The two scenarios bound the possible range of plutonium diffusion and its associated effect in neutronic performance.

\section{5. "STEPWISE" CALCULATION OF PLUTONIUM DIFFUSION}

A Python script was developed to simulate the maximum diffusion case after every burnup step calculated in Serpent. Fig. 10 shows the Python routine for the "stepwise" plutonium diffusion and the steps of the python routine are as follows; 1) Set the initial material definition and burnup step for Serpent. 2) Run Serpent to calculate the value of $\mathrm{k}_{\text {eff }}$ at the current time step and after the next burnup time step. 3) Simulate plutonium diffusion into fuel salt by updating material definition $-\mathrm{All}{ }^{239} \mathrm{Pu}$ atoms are transferred from the blanket regions and into the fuel salt, homogenously distributed across the 8 axial fuel regions. 4) Update burnup step value for the next Serpent calculation. 5) Repeat step 2 until the specified burnup steps are completed.

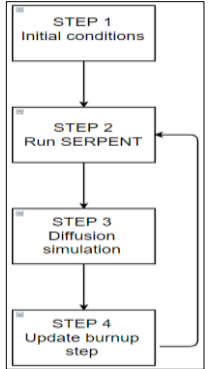

Figure 10.

\section{NEUTRONIC MARGIN ANALYSIS}

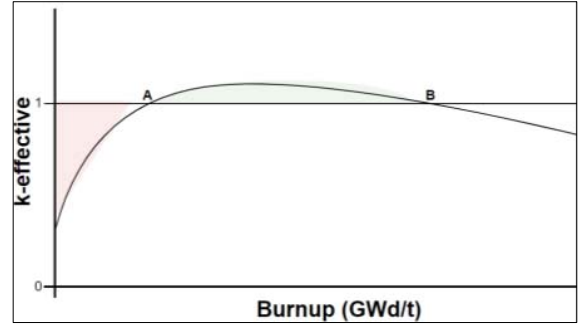

Figure 11. Representative reactivityburnup curve.

The concept of neutron excess $(\Delta \mathrm{N})$ was introduced by Petroski [9] to quantify the difference between the total neutron production $(\Delta \mathrm{P})$ and the total neutron absorption $(\triangle \mathrm{A})$ in the fuel (including losses through neutron leakage) over the burnup period. Fig. 11 shows a reactivity-burnup curve of a representative system and based on the concept of neutron excess, the numerical difference between the areas in green and red indicate the "neutronic margin" (NM) the system. The areas in red and green will be referred to as NM- and NM+ respectively. Point A on Fig. 11 indicates the minimum burnup (minBU) requirement for breed-and-burn operation and point $\mathrm{B}$ is the maximum theoretical burnup (maxBU) when the fuel is no longer producing neutrons. Parametric studies were performed to investigate the effects of BBMSR core and U-tube geometry on $\mathrm{k}_{\mathrm{eff}}$ and neutronic margin.

\subsection{Axial Reflector Thickness}

To investigate the neutronic effect of thickness of coolant layer above and below the core, a core height $\left(\mathrm{h}_{\mathrm{c}}\right)$ of $160 \mathrm{~cm}$ (like the Moltex SSR) was modeled, without the U-tube blanket. With molten salt coolant as axial

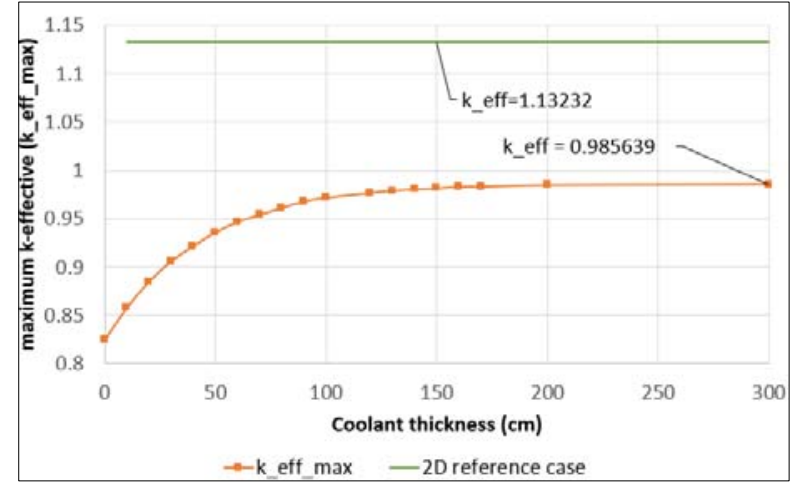

Figure 12. Keff_max versus burnup (coolant thickness).

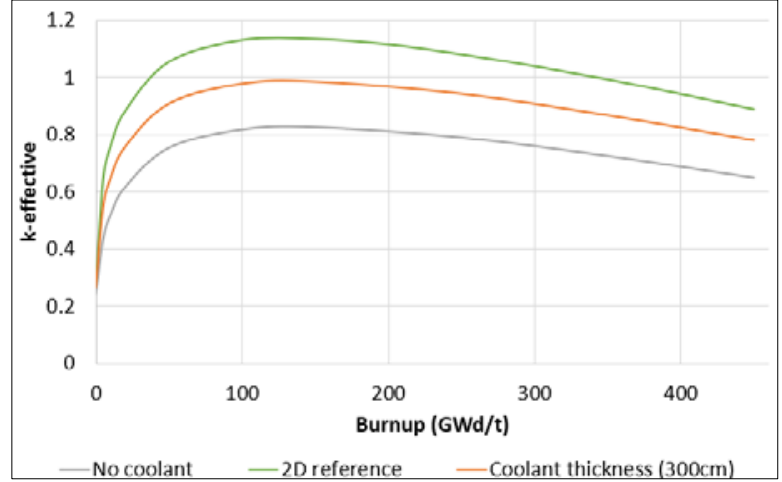

Figure 13. Reactivity-burnup $(300 \mathrm{~cm}$ coolant). 
reflectors, neutrons were partially reflected back into the system which improved neutronic performance, but not sufficiently to achieve breed-and-burn operation. Fig. 12 shows the trend of maximum $k_{\text {eff }}$ as a function of axial reflector thickness ranging from $0 \mathrm{~cm}$ to $300 \mathrm{~cm}$, compared to the $\mathrm{k}_{\text {eff_max }}$ achieved by a 2D reference simulation, i.e., no leakage. With increasing reflector thickness, $\mathrm{k}_{\text {eff_max }}$ converges to 0.99 . Fig. 13 shows the reactivity-burnup curve for the $2 \mathrm{D}$ case; no axial reflector; and $300 \mathrm{~cm}$ coolant thickness.

\subsection{Core Height $\left(h_{c}\right)$}

The neutronic performance of the system improves with increasing core height $\left(\mathrm{h}_{\mathrm{c}}\right)$, since the fuel volume fraction increases relative to axial leakage. Parametric study of the BBMSR core height from $160 \mathrm{~cm}$ to $1200 \mathrm{~cm}$ was performed, with a fixed coolant thickness of $160 \mathrm{~cm}$ and no U-tube blanket. Fig. 14 shows the simulated $\mathrm{k}_{\text {eff_max }}$ as a function of core height, compared to the $2 \mathrm{D}$ reference case. The neutronic performance improves with increasing core height and eventually converges towards the $2 \mathrm{D}$ case. Fig. 15 and Table I show the reactivity-burnup curve and results of the neutronic margin analysis. At $h_{c}=320 \mathrm{~cm}$, the net neutronic margin is close to zero. At $h_{c}=1400 \mathrm{~cm}$, the system achieves a minimum burnup comparable to the $2 \mathrm{D}$ case, with a $26 \%$ lower NM. It would be appropriate to consider a maximum BBMSR core height of $400 \mathrm{~cm}$ (similar to LWR fuel pins), which has 77\% lower NM compared to the 2D case.

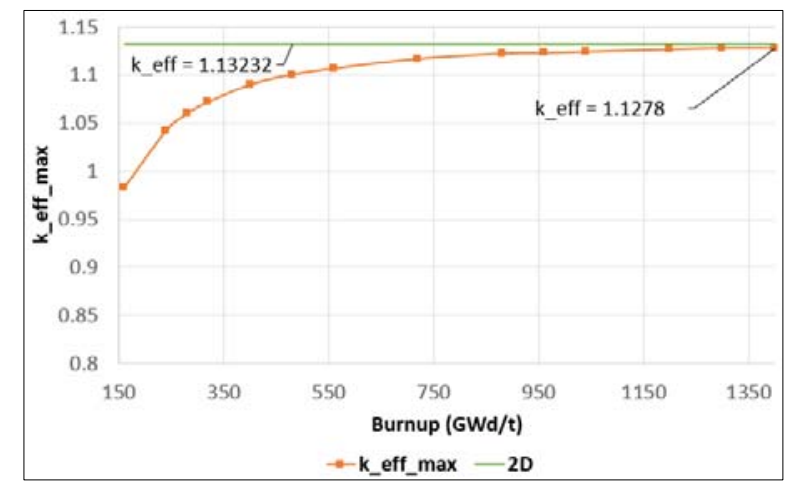

Figure 14. $k_{\text {eff_max }}$ versus burnup $\left(h_{c}\right)$.

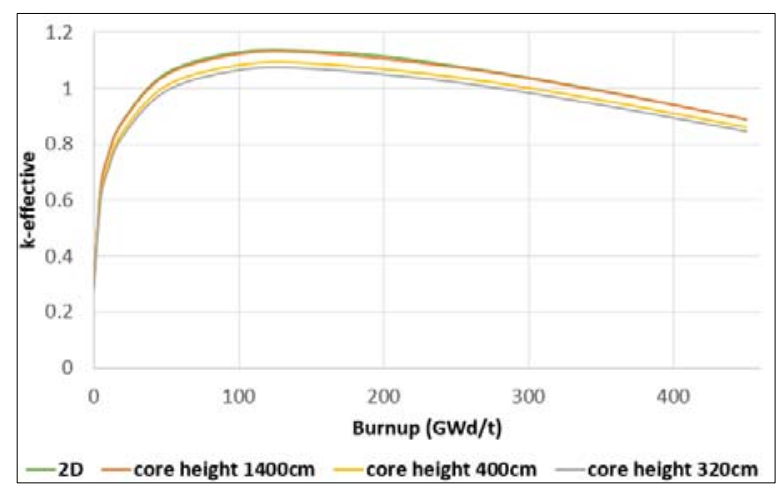

Figure 15. Reactivity-burnup curve $\left(h_{c}\right)$.

Table I. Neutronic margin analysis for core height compared to 2D reference case.

\begin{tabular}{|l|c|c|c|c|}
\hline & NM & NM diff. from 2D & $\operatorname{minBU}(\mathrm{GWd} / \mathrm{t})$ & $\operatorname{maxBU}(\mathrm{GWd} / \mathrm{t})$ \\
\hline $2 \mathrm{D}$ reference & 17.99 & - & 36 & 342 \\
\hline $\mathrm{h}_{\mathrm{c}}=1400 \mathrm{~cm}$ & 13.36 & $-26 \%$ & 36 & 338 \\
\hline $\mathrm{h}_{\mathrm{c}}=400 \mathrm{~cm}$ & 4.22 & $-77 \%$ & 46 & 301 \\
\hline $\mathrm{h}_{\mathrm{c}}=320 \mathrm{~cm}$ & -0.28 & $-102 \%$ & 61 & 280 \\
\hline
\end{tabular}

\subsection{Natural Uranium Metal to Fuel Salt Volume Ratio ( ()}

A parametric study of the neutronic effect of U-tube blanket volume was performed for both the maximum plutonium diffusion and zero plutonium diffusion scenarios. The fuel salt was kept at a fixed volume of $6031 \mathrm{~cm}^{3}$, corresponding to $h_{c}=320 \mathrm{~cm}$ when $N M \approx 0$. The increase volume of U-Tube blanket, i.e., increase in natural uranium metal to fuel salt volume ratio $(\Upsilon)$, was offset by the increase of the core height. Table II gives some examples of $\Upsilon$ ratio with the corresponding BBMSR and U-Tube geometry, where A1 is the area inside the blanket and A2 is the area outside, as illustrated in Fig. 16. The study was performed for $\Upsilon=0 \%$ to $69 \%\left(\mathrm{~h}_{\mathrm{c}}=320 \mathrm{~cm}\right.$ to $\left.540 \mathrm{~cm}\right)$ with coolant

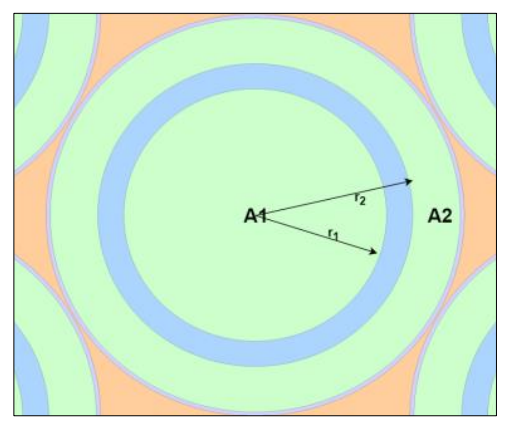

Figure 16. Centre and outer flow area of $Y=22 \%(390 \mathrm{~cm})$. height of $70 \mathrm{~cm}$ which results in a $\mathrm{k}_{\mathrm{eff}}$ that approaches $(4 \%$ lower) the asymptotic value shown in section 
6.1. The geometric parameters of this analysis are based on the previous thermal-hydraulic study of the BBMSR, which showed that natural convection is optimized when A1=A2 [6].

Table II. Examples of BBMSR geometry with U-Tube with respect to $\Upsilon$ ratio.

\begin{tabular}{|c|c|c|c|c|c|c|}
\hline $\begin{array}{c}\text { Core height } \\
\mathrm{h}_{\mathrm{c}}(\mathrm{cm})\end{array}$ & $\begin{array}{c}\mathrm{U} \text {-Tube } \\
\mathrm{r}_{1}(\mathrm{~cm})\end{array}$ & $\begin{array}{c}\text { U-Tube } \\
\mathrm{r}_{2}(\mathrm{~cm})\end{array}$ & $\begin{array}{c}\text { U-Tube volume } \\
\left(\mathrm{cm}^{3}\right)\end{array}$ & $\begin{array}{c}\text { Fuel volume } \\
\mathrm{A} 1\left(\mathrm{~cm}^{3}\right)\end{array}$ & $\begin{array}{c}\text { Fuel volume } \\
\mathrm{A} 2\left(\mathrm{~cm}^{3}\right)\end{array}$ & $\begin{array}{c}\mathrm{Y} \text { ratio } \\
(\%)\end{array}$ \\
\hline 320 & 0 & 0 & 0 & 0 & 6031 & 0 \\
\hline 390 & 1.569 & 1.881 & 1319.35 & 3015.5 & 3015.5 & 22 \\
\hline 480 & 1.415 & 2.000 & 3015.66 & 3015.5 & 3015.5 & 50 \\
\hline
\end{tabular}

Fig. 17 shows the increase in neutronic margin NM as a function of $\Upsilon$ ratio, with NM converging after $\mathrm{Y}=50 \%$ in the maximum diffusion scenario, but continuing to increase in the zero diffusion scenario. Fig. 18 shows the NM percentage difference between the maximum and zero diffusion bounding scenarios, with a maximum difference of $10 \%$ at $\Upsilon=22 \%\left(\mathrm{~h}_{\mathrm{c}}=390 \mathrm{~cm}\right)$ and $0 \%$ difference at $\Upsilon=50 \%(\mathrm{hc}=480 \mathrm{~cm})$. Fig. $19-$ 20 show the reactivity-burnup curves and Table III gives the neutronic margin analysis for $\Upsilon$ ratio of $22 \%$ $(390 \mathrm{~cm})$ and $50 \%(480 \mathrm{~cm})$ in both diffusion scenarios. With $\Upsilon=22 \%, \mathrm{NM}$ is $176-207 \%$ greater than the $2 \mathrm{D}$ case, while with $\Upsilon=50 \% \mathrm{NM}$ is $295 \%$ greater.

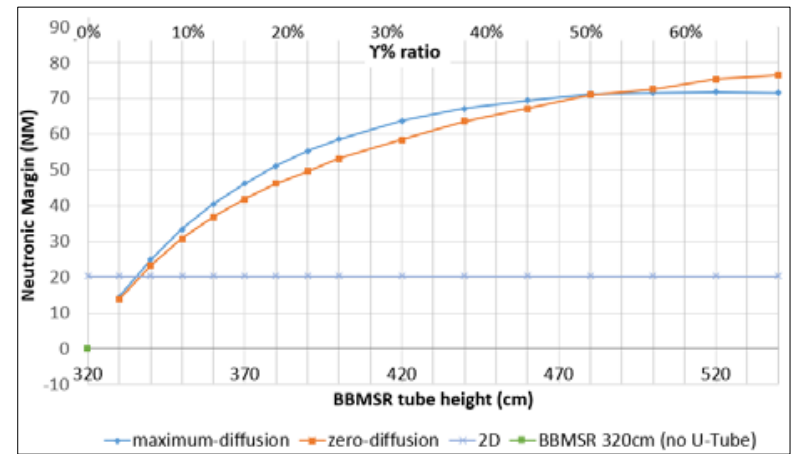

Figure 17. NM with increasing $\Upsilon \%$ ratio.

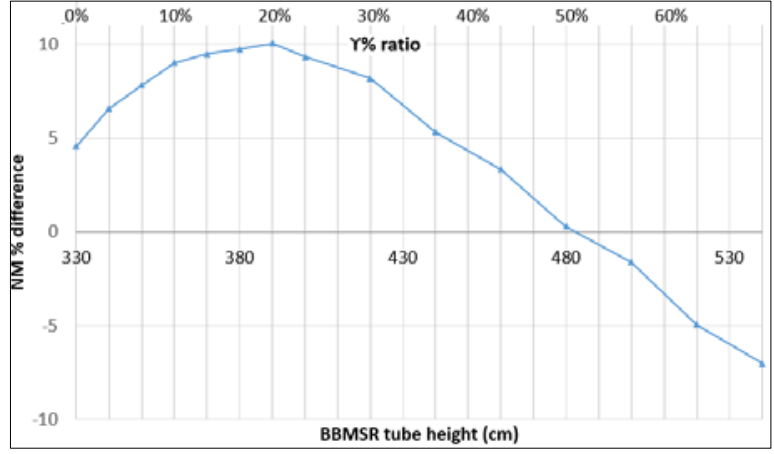

Figure 18. NM \% difference.

Table III. Results of NM analysis for $\Upsilon$ ratio: $22 \%(390 \mathrm{~cm})$ and $50 \%(480 \mathrm{~cm})$.

\begin{tabular}{|c|c|c|c|c|}
\hline & NM & NM diff. from 2D & $\operatorname{minBU}(\mathrm{GWd} / \mathrm{t})$ & $\operatorname{maxBU}(\mathrm{GWd} / \mathrm{t})$ \\
\hline 2D reference & 17.99 & - & 36 & 342 \\
\hline$\Upsilon=0 \% \mathrm{~h}_{\mathrm{c}}=320 \mathrm{~cm}$ & -0.28 & $-102 \%$ & 61 & 280 \\
\hline$\Upsilon=22 \%(390 \mathrm{~cm})$ max-diffusion & 55.26 & $207 \%$ & 30 & 505 \\
\hline$\Upsilon=22 \%(390 \mathrm{~cm})$ zero-diffusion & 49.69 & $176 \%$ & 25 & 490 \\
\hline$\Upsilon=50 \%(480 \mathrm{~cm})$ max-diffusion & 71.23 & $296 \%$ & 25 & 500 \\
\hline$\Upsilon=50 \%(480 \mathrm{~cm})$ zero-diffusion & 71.03 & $295 \%$ & 20 & 500 \\
\hline
\end{tabular}

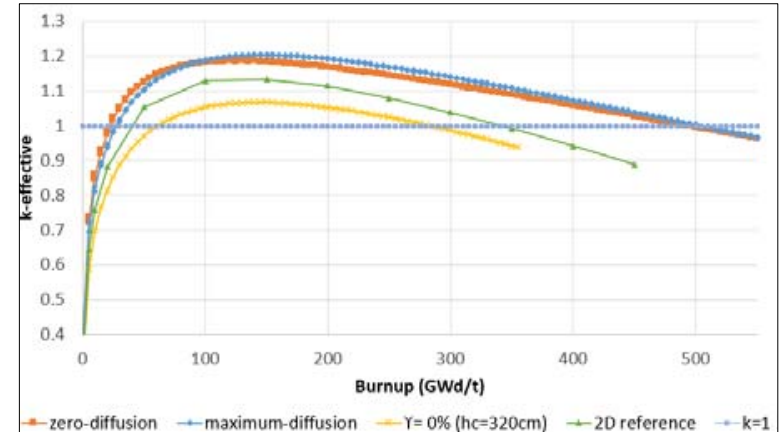

Figure 19. Reactivity-burnup curve for $Y=22 \%$

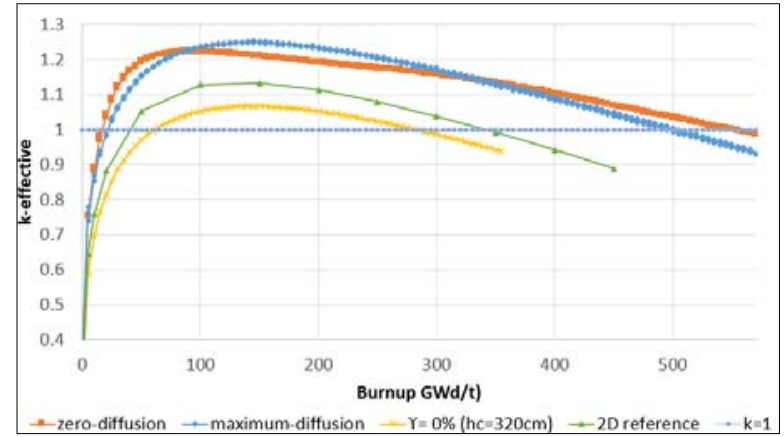

Figure 20. Reactivity-burnup curve for $\mathrm{Y}=\mathbf{5 0} \%$ 
Fig. 21 shows that minimum burnup is inversely related to the $\Upsilon$ ratio. Fig. 22 shows the maximum theoretical burnup values with respect to $\Upsilon$ ratio, and the zero-diffusion case achieves a higher maximum burnup than the maximum-diffusion case. Fig. 23 and 24 illustrate the fission power distribution for both maximum- and zero-diffusion case with $\Upsilon=69 \%\left(\mathrm{~h}_{\mathrm{c}}=540 \mathrm{~cm}\right)$ at burnup steps 40,200 and $420 \mathrm{GWd} / \mathrm{t}$. These figures are generated in Serpent, with shades of red and yellow representing relative fission power and shades of blue representing relative thermal flux [5]. In the maximum-diffusion case, fission power remains at the axial centre of the core (Fig. 23). In the zero-diffusion case (Fig. 24) the fission wave propagates away from the centre, due to the travelling "fission wave" effect observed in solid-fuel breed-and-burn reactors [10]. Fig. 25 and 26 shows the quantity of plutonium atoms in the fuel salt and U-Tube blanket at $\Upsilon=69 \%\left(\mathrm{~h}_{\mathrm{c}}=540 \mathrm{~cm}\right)$ both for maximum and zero plutonium diffusion bounding case.

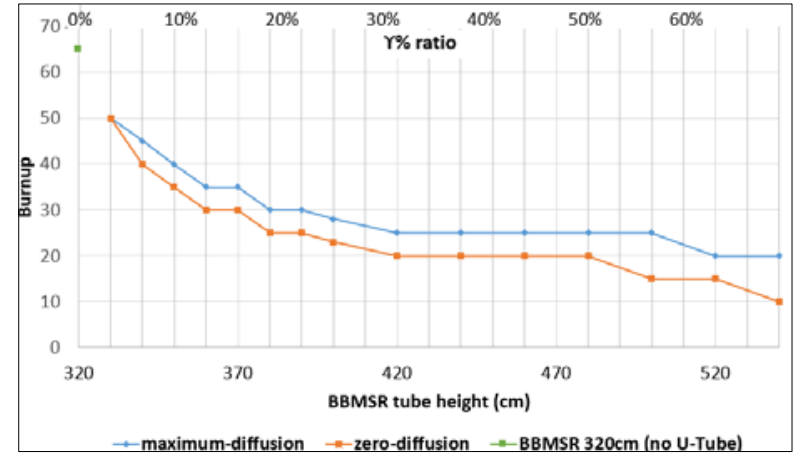

Figure 21. Minimum burnup versus $\Upsilon \%$ ratio

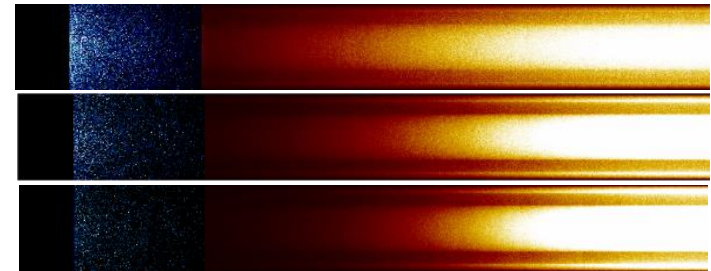

Figure 23. Fission power distribution for Maximum-diffusion case, $\Upsilon=\mathbf{6 9 \%}$ : burnup steps 40,200 , and $420 \mathrm{GWd} / \mathrm{t}$ (top to bottom).

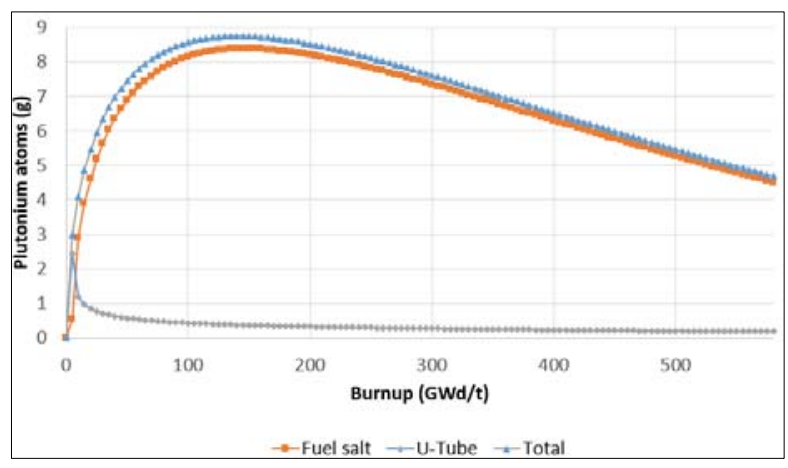

Figure 25. Plutonium build up versus burnup at $\Upsilon=69 \%\left(h_{c}=540 \mathrm{~cm}\right)$; Maximum-diffusion case

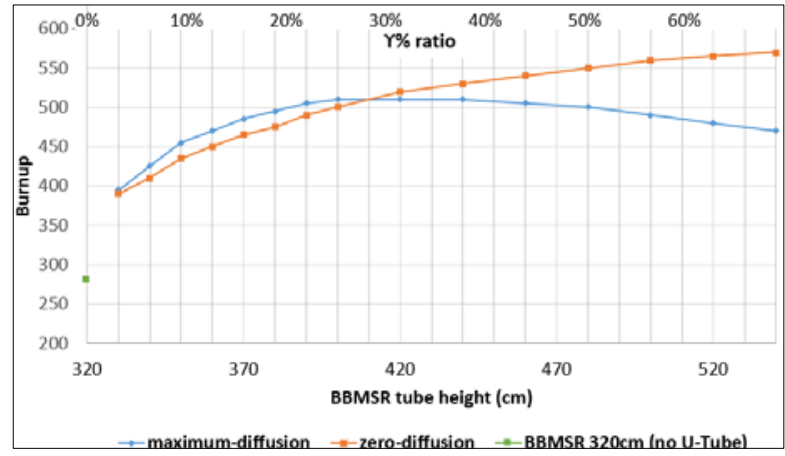

Figure 22. Maximum burnup versus $\Upsilon \%$ ratio

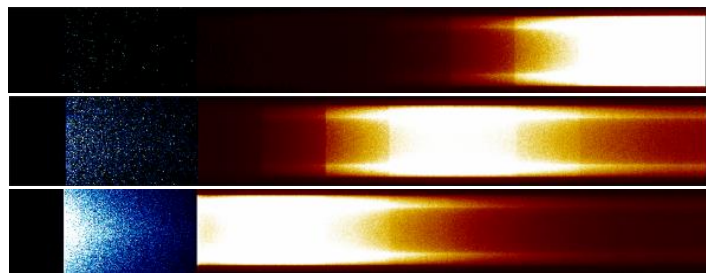

Figure 24. Fission power distribution for

Zero-diffusion case, $\mathbf{r}=\mathbf{6 9 \%}$ : burnup steps 40,200 , and $420 \mathrm{GWd} / \mathrm{t}$ (top to bottom).

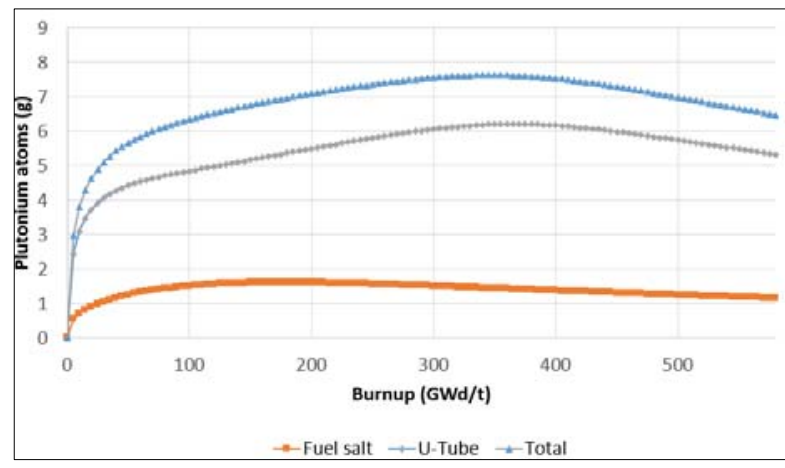

Figure 26. Plutonium build up versus burnup at $\mathrm{Y}=69 \%\left(\mathrm{~h}_{\mathrm{c}}=540 \mathrm{~cm}\right)$; Zero-diffusion case

In the maximum-diffusion case, plutonium bred initially in the blanket immediately diffuses into the fuel salt. Fission of plutonium in the fuel salt generates extra neutrons which enables more effective plutonium breeding in the fuel salt, hence a higher minimum burnup and a higher $\mathrm{k}_{\text {eff }}$ compared to zero-diffusion case. However, as the flux remains concentrated at the centre of the core due to axial leakage, ${ }^{238} \mathrm{U}$ is soon 
depleted in the centre region of the blanket, so breeding primarily occurs in the lower-density fuel salt thereafter. In the zero-diffusion case, neutron flux is initially concentrated at the axial centre of the core, so ${ }^{239} \mathrm{Pu}$ breeding and fission are also concentrated at the centre. As the ${ }^{239} \mathrm{Pu}$ fissions and produces neutrons, the adjacent regions breed more ${ }^{239} \mathrm{Pu}$, resulting in the outward propagation of the fission wave inside the blanket material. Since it takes longer for all the ${ }^{238} \mathrm{U}$ and ${ }^{239} \mathrm{Pu}$ along the length of the blanket to be depleted, the zero-diffusion case has a higher "maximum burnup" than the maximum-diffusion case. In both cases power generation is driven by the U-Tube blanket, as the density of the natural uranium metal is up to 3 times that of the fuel salt which results in a higher rate of breeding [11]. Due to the concentrated heat generation, thermal limits and sufficient cooling of the breeding blanket will have to be considered in further research.

\section{CONCLUSION}

Based on previous study of the breed-and-burn molten salt fuel tube design, a 3D pin cell parametric study was conducted to investigate the increase in neutronic performance of the BBMSR. Performance was first improved by increasing the axial reflector thickness and the core height of the fuel tube design. While breed-and-burn operation was shown to be viable, a realistic core height of 4 meters achieves $77 \%$ less neutronic margin compared to the $2 \mathrm{D}$ reference case. Further neutronic improvement was achieved using a concentric natural uranium metal tubular breeding blanket (U-Tube) within the fuel tube. Assuming all the plutonium bred in the U-Tube blanket diffuses into the salt to form plutonium trichloride, a gain in neutronic performance of up to $296 \%$ was possible with a blanket-to-salt volume ratio of $\Upsilon=50 \%$ (core height $480 \mathrm{~cm}$ ). At $\Upsilon=22 \%$ (core height $390 \mathrm{~cm}$ ), the neutronic performance was improved by $176-207 \%$. This study shows the neutronic performance of the BBMSR can be significantly improved by using the U-Tube breeding blanket design. However, further research is needed for diffusion of plutonium from the blanket into the fuel salt and the thermal-hydraulic effect of the U-Tube blanket, which generates most of the fission power.

\section{REFERENCES}

1. H. Sekimoto, K. Ryu, Y. Yoshimura, "CANDLE: The New Burnup Strategy," Nuclear Science and Engineering. 139(3), pp. 306-317 (2001).

2. T.J. Dolan, Molten Salt Reactors and Thorium Energy, chapter 1, Woodhead Publishing, Duxford, United Kingdom (2017).

3. I. Scott, T. Abram, and O. Negri, "Stable Salt Reactor Design Concept," Proceedings of the Thorium Energy Conference, Mumbai, India (2015).

4. A. Kasam, E. Shwageraus, "Feasibility Studies of a Breed and Burn Molten Salt Reactor," Proceedings of ICAPP 2017, Fukui and Kyoto, Japan (2017).

5. J. Leppänen, "Serpent - a Continuous-energy Monte Carlo Reactor Physics Burnup Calculation Code," VTT Technical Research Centre of Finland. (2015).

6. A. Kasam, E. Shwageraus, J.I. Lee, "Numerical study of heat transfer in ascending mixed convection with internal heat generation," Annals of Nuclear Energy. 133 pp. 138-144 (2019).

7. S.J. Rothman, L.T. Lloyd, R. Weil, A.L. Harkness, "Self-Diffusion in Gamma Uranium," Argonne National Laboratory, Partial Report - Metallurgy Division Program 4.1.2. (1959).

8. Private communication with Dr. Ian Scott of Moltex Energy ltd.

9. R. Petroski, B. Forget, C. Forsberg, "Neutronic Characteristics of Linear-Assembly Breed-and-Burn Reactors," Nuclear Engineering and Design. 250 pp. 364-384 (2012).

10. J. Gilleland, R. Petroski, K. Weaver, "The Traveling Wave Reactor: Design and Development," Engineering. 2 pp. 88-96 (2016).

11. V. N. Desyatnik, S.F. Katyshev, S.P. Raspopin, Yu.F. Chervinskii, "Density, surface tension, and viscosity of uranium trichloride-sodium chloride melts," Soviet Atomic Energy. 39(1) pp. 649-651 (1975). 